\title{
ANÁLISE ESTRATIGRÁFICA DA SEQUÊNCIA SILURIANA DA BACIA DO PARNAÍBA, NORDESTE DO BRASIL
}

\author{
STRATIGRAPHIC ANALYSIS OF SILURIAN SEQUENCE OF PARNAÍBA SEDIMENTARY BASIN, \\ NORTHEAST BRAZIL
}

\section{Erlanny M. Alves CRUZ ${ }^{1,2}$, Valéria Centurion CÓRDOBA ${ }^{1,2,3}$, Débora do Carmo SOUSA ${ }^{2,3}$}

${ }^{1}$ Programa de Pós-Graduação em Geodinâmica e Geofísica - Universidade Federal do Rio Grande do Norte; Av. Senador Salgado Filho, 3000 - Campus Universitário. Natal - RN. Email: erlanny.m.alves@ gmail.com

${ }^{2}$ Laboratório de Geologia e Geofísica do Petróleo UFRN; CP. 1639 - CEP 59078-970 - Natal - RN. Email: valeria.geo@ufrnet.br

${ }^{3}$ Departamento de Geologia - Centro de Ciências Exatas e da Terra - UFRN. Natal - RN. Email: debora@ geologia.ufrn.br

\author{
Introdução \\ Base de Dados e Métodos \\ Contextualização Geológica \\ Evolução Tectonossedimentar \\ Arcabouço Estratigráfico \\ Análise Estratigráfica \\ Estratigrafia de Sucessões Fluviais \\ Análise 1D \\ Análise 2D \\ Análise da Seção Estratigráfica \\ Modelos Estratigráficos Evolutivos \\ Proposta Estratigráfica para a Sequência Siluriana \\ Considerações Finais \\ Agradecimentos \\ Referências
}

\begin{abstract}
RESUMO - Baseado no modelo da Estratigrafia de Sequências, o presente trabalho compreende uma análise estratigráfica da seção siluriana da Bacia do Parnaíba a partir da interpretação de perfis de poços e dados sísmicos. Esta análise permitiu reconhecer as fácies sedimentares, interpretar os sistemas deposicionais e definir os ciclos e conjuntos de ciclos, os quais possibilitaram identificar os tratos de sistemas que compõem a Sequência Siluriana. Seguindo esta concepção, essa sequência, litoestratigraficamente equivalente às formações Ipu, Tianguá e Jaicós, pôde ser compartimentada em cinco seções cronoestratigráficas de menor hierarquia, levando-se em consideração distintas tendências de variação do nível de base, e consequente variação do espaço de acomodação, sendo estes: Trato de Sistemas de Nível de Base Baixo precoce (pequeno espaço de acomodação), de Nível de Base Baixo tardio (moderado espaço de acomodação), Transgressivo (grande espaço de acomodação), de Nível de Base Alto precoce (moderado espaço de acomodação) e, por fim, de Nível de Base Alto tardio (pequeno espaço de acomodação). Este arranjo estratigráfico atesta que a evolução desta sequência é pontuada por um ciclo completo transgressivo-regressivo.
\end{abstract}

Palavras-Chaves: Bacia do Parnaíba; Estratigrafia de Sequências; Sequência Siluriana.

ABSTRACT - Based on the concepts of Sequence Stratigraphy this review presents a stratigraphy analysis of the Silurian Section of Parnaiba Basin according to well-logs and seismic data interpretation. According to this model, it was possible to define the sedimentary facies, the depositional systems, as well as the cycles and the cycle sets, allowing the identification of the systems tracts that make part of the Silurian Sequence. Following this assumption, the Silurian Sequence which is related to Ipu, Tianguá and Jaicós formations, can be divided into five intervals, according to the increase and decrease trends in the accommodation: Early Lowstand Systems Tract (low accommodation), Late Lowstand (moderate accommodation), Transgressive (high accommodation), Early Highstand (moderate accommodation) and finally, Late Highstand (low accommodation). This stratigraphic arrangement proves that the evolution of the Silurian Section is characterized by a complete transgressive-regressive cycle.

Keywords: Parnaiba Basin; Sequence Stratigraphy; Silurian Sequence.

\section{INTRODUÇÃO}

A Bacia do Parnaíba abrange uma área de aproximadamente 600 mil $\mathrm{km}^{2}$ da porção noroeste do Nordeste do Brasil. Compreende uma área sedimentar que engloba os estados do Maranhão, Piauí, Tocantins, Pará, Ceará e Bahia (Figura 1). Trata-se de uma sinéclise paleozoica com geometria elíptica e eixo maior com direção NESW. A Sequência Siluriana, foco deste estudo, compreende a seção mais basal da Bacia do
Parnaíba sendo representada, em termos litoestratigráficos pelo Grupo Serra Grande. Esse grupo é formado por sucessões sedimentares diferenciadas, que se inicia com depósitos fluviais (Formação Ipu), sobrepostos por depósitos marinhos (Formação Tianguá) e, estes, sotopostos a depósitos fluviais (Formação Jaicós).

Esta sequência representa o primeiro ciclo transgressivo-regressivo da Bacia do Parnaíba, 
ocorrido em um contexto de sinéclise, e registra as variações no mar epéirico que se processaram durante o Siluriano. Estudos estratigráficos de cunho genético ainda são escassos para essa sequência deposicional e, por isso, visando suprir esta lacuna, foi realizada, neste trabalho, uma análise estratigráfica detalhada da Sequência Siluriana da Bacia do Parnaíba, utilizando-se os conceitos e premissas da estratigrafia de sequências mediante a interpretação de dados de poços e dados sísmicos.

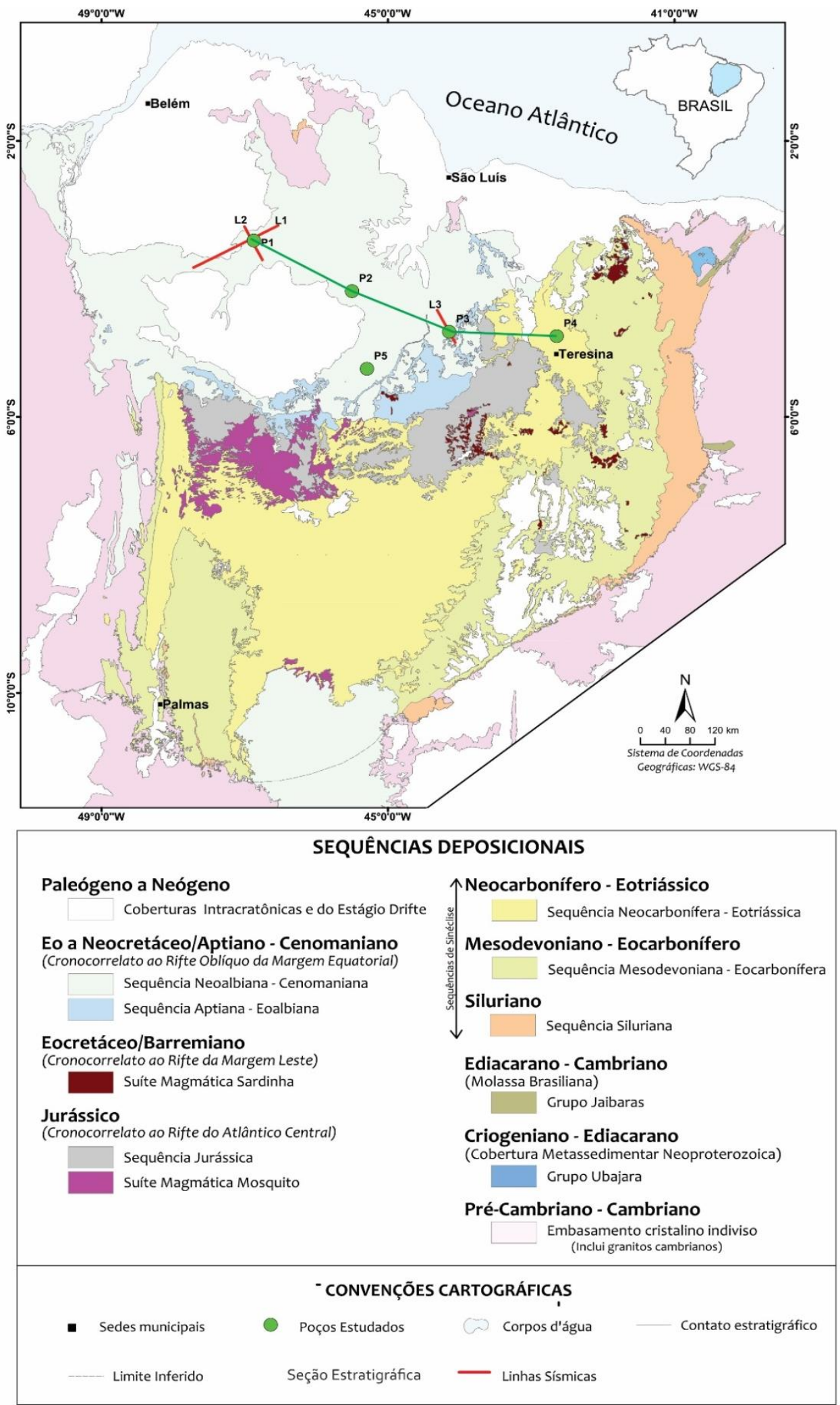

Figura 1 - Mapa geológico da Bacia do Parnaíba elaborado no âmbito do Projeto BPAR (Chevron/UFRN/FUNPEC) a partir de modificações nas cartas ao milionésimo da CPRM. Este mapa apresenta a localização dos poços e das linhas sísmicas analisados e da seção estratigráfica. 


\section{BASE DE DADOS E MÉTODOS}

A base de dados disponível para este estudo compreende cinco poços de sondagem denominados P1, P2, P3, P4 e P5, constituídos pelas pastas dos poços e de perfis compostos, os quais abrangem perfis geofísicos e colunas litológicas, além de três linhas sísmicas que os contêm, aqui referidas por L1, L2 e L3 (Figura 1). Essa base de dados foi previamente fornecida pelo Projeto de Pesquisa "Geologia e Sistemas Petrolíferos da Bacia Intracratônica do Parnaíba" (BPAR) financiado por um convênio entre a Chevron Brasil e o Programa de Pós-Graduação em Geodinâmica e Geofísica da Universidade Federal do Rio Grande do Norte (PPGG - UFRN). Além disso, a base de dados contou com um acervo bibliográfico sobre a geologia da Bacia do Parnaíba, especialmente da Seção Siluriana e também dos métodos a serem empregados.

$\mathrm{O}$ desenvolvimento desta pesquisa teve início com uma compilação bibliográfica dos principais trabalhos realizados na Bacia do Parnaíba, visando com isso aprofundar os conhecimentos acerca da área de estudo, bem como sobre os métodos de análise estratigráfica de sucessões fluviais e parálicas. Partiu-se, então, para a análise estratigráfica da Sequência Siluriana, alvo deste estudo, que englobou duas etapas: a análise detalhada dos poços, denominada análise 1D, seguida da interpretação sísmica e elaboração da seção estratigráfica, denominadas análise 2D.

Sendo a base de dados exclusivamente de subsuperfície, a definição das litofácies baseou-se na litologia e nos padrões dos perfis de raios gama, tendo como suporte fotos de afloramentos obtidas no decurso do projeto BPAR por outros pesquisadores. Desta forma, a caracterização das fácies e dos sitemas deposicionais derivou-se das fontes bibliográficas utilizadas.

Assim, na análise 1D, com base nos perfis litológicos ecom o auxílio dos padrões dos perfis de raios gama, os quais evidenciaram tendências de aumento ou diminuição textural das litofácies foram delimitados os ciclos e definidos os padrões de ciclicidade, bem como identificadas as superfícies-chave e as unidades genéticas da estratigrafia de sequências.

O termo ciclo, empregado neste trabalho, apresenta a mesma hierarquia das parassequências, que são consideradas ciclos de $4^{\mathrm{a}}$ ordem (Emery \& Myers, 1996). No entanto, ciclo é um termo que apresenta maior abrangência do que a terminologia parassequência, idealizada para o uso em contextos marinhos (sensu Van Wagoner et al., 1990), podendo, aquele, ser empregado em qualquer contexto ambiental, inclusive $o$ continental.

O reconhecimento das superfícies-chave foi de fundamental importância para a elaboração do arcabouço estratigráfico. As de menor hierarquia, que limitam os ciclos, foram marcadas mediante o reconhecimento de uma mudança brusca de litofácies.

No caso das superfícies limitantes dos ciclos fluviais, estas foram posicionadas na passagem entre pelitos de planície de inundação para arenitos de fundo de canal, já nos ciclos plataformais, estas superfícies foram identificadas na passagem entre arenitos marinhos mais proximais para pelitos mais distais.

As superfícies de máxima transgressão, de inundação máxima e as discordâncias-limites, de hierarquia superior, foram posicionadas na transição entre conjuntos de ciclos com padrões de empilhamento distintos.

Ao final da análise 1D, que contou também com a confecção de histogramas de frequências de litofácies, os quais foram elaborados visando auxiliar na construção de uma curva idealizada de variação do nível de base para a seção estudada, todos os resultados foram integrados em um diagrama $1 \mathrm{D}$, elaborado para cada poço estudado.

$\mathrm{Na}$ análise 2D foi confeccionada uma seção estratigráfica NW-SE, com base na correlação entre as superfícies-chave e as unidades genéticas, identificadas durante a análise $1 \mathrm{D}$, nos quatro poços estudados. Nesta etapa também foi realizada a análise sismoestratigráfica das três linhas sísmicas selecionadas.

A calibração sísmica-poço, fundamental para atestar a confiabilidade dos resultados, foi realizada utilizando-se os checkshots no software OpendTect.

Este método consiste na medição do tempo de percurso da onda sísmica desde sua fonte até um receptor situado dentro do poço. Tem-se como resultado deste procedimento funções que relacionam tempo e profundidade, as quais podem ser usadas para a conversão da profundidade em tempo ou do tempo em 
profundidade. $\mathrm{Na}$ análise sismoestratigráfica, que também foi apoiada pela análise $1 \mathrm{D}$, focou-se no reconhecimento das sismofácies e dos refletores que representam as superfícies-chave.

Durante a última etapa de trabalho, foram elaborados modelos estratigráficos evolutivos idealizados para a Sequência Siluriana da Bacia do Parnaíba, os quais permitiram seu melhor entendimento, bem como a apresentação de uma nova proposta estratigráfica para esta sequência.

\section{CONTEXTUALIZAÇÃO GEOLÓGICA}

\section{Evolução Tectonossedimentar}

A origem da Bacia do Parnaíba é associada a pulsos magmáticos ocorridos durante o final do ciclo Brasiliano, os quais propiciaram a formação de grábens ou riftes com eixos de direção N-NE (Góes et al., 1990).

Em resposta a esses pulsos magmáticos estabeleceu-se uma grande depressão ordovicianasiluriana, onde se depositaram os sedimentos fluviais a marinhos rasos hoje pertencentes ao Grupo Serra Grande (formações Ipu, Tianguá e Jaicós).

O final dessa deposição é marcado pela Orogenia Caledoniana, que resultou em uma discordância de caráter regional (Góes et al., 1990).

A continuação desses processos termais, associados aos pulsos magmáticos ocorridos desde o final do ciclo Brasiliano, aliados aos flexurais resultou em um aumento na área de sedimentação (Góes et al., 1990). Essa expansão é testemunhada pela presença das rochas sedimentares do Grupo Canindé. O encerramento desse ciclo de sedimentação é marcado por uma discordância regional relacionada à Orogenia EoHerciniana (Góes et al., 1990).

No Neocarbonífero, a sedimentação foi retomada com deposição registrada pelas rochas que compõem o Grupo Balsas. Nesta fase houve progressiva desertificação e deslocamento dos depocentros para a porção central da bacia (Góes et al., 1990).

No Juro-Triássico, durante a fragmentação inicial de Gondwana, desenvolveu-se significativo processo magmático, seguido pela deposição da Formação Pastos Bons (Vaz et al., 2007).

$\mathrm{O}$ ciclo sedimentar encerra-se no Cretáceo e assinala duas fases distintas: a primeira relacionada ao magmatismo Eocretáceo, associado com a abertura do Atlântico Sul; e a segunda diz respeito à deposição lacustre a continental das formações Codó, Corda, Grajaú e Itapecuru (Góes et al., 1990).

\section{Arcabouço Estratigráfico}

Os registros sedimentares que ocorrem na Bacia do Parnaíba foram agrupados, segundo Vaz et al. (2007), em cinco grandes sequências, todas delimitadas por discordâncias (Figura 2), a saber: sequências Siluriana (Grupo Serra Grande), Mesodevoniana-Eocarbonífera (Grupo Canindé), Neocarbonífera-Eotriássica (Grupo Balsas), Jurássica (Formação Pastos Bons) e Cretácea (formações Codó, Corda, Grajaú e Itapecurú). A figura 1 apresenta o mapa geológico da Bacia do Parnaíba e as áreas de exposição dessas sequências deposicionais.

A Sequência Siluriana é representada pelo Grupo Serra Grande. A designação Serra Grande foi inicialmente proposta por Small (1914) para descrever uma seção composta por arenitos, conglomerados e calcários da Bacia do Parnaíba e calcários da Bacia de Ubajara. Por sua vez, Kegel (1953) excluiu as rochas carbonáticas e referiu-se à sequência sedimentar inferior da bacia como formação, de acordo com a presença de uma discordância angular que separa as rochas destas duas bacias. Posteriormente, Carozzi et al. (1975) elevaram esta formação à categoria de grupo, e Caputo (1984) e Caputo \& Lima (1984) sugeriram a subdivisão do Grupo Serra Grande em três formações (Ipú, Tianguá e Jaicós), como é consensualmente aceito até os dias atuais. $\mathrm{O}$ Grupo Serra Grande, em subsuperfície, ocorre praticamente em toda a extensão da bacia. Contudo, sua área aflorante é restrita a uma estreita faixa no leste da bacia, bordejada por rochas do embasamento (Figura 1).

Esse grupo é formado por sucessões sedimentares diferenciadas, iniciando com uma sucessão continental fluvial, sobreposta por uma sucessão marinha e, em seguida, retornando a uma sucessão continental fluvial, constituindo, dessa forma, um amplo ciclo transgressivo-regressivo completo (Caputo \& Lima 1984).

A primeira sucessão continental é tipificada pelos litótipos da Formação Ipu, terminologia inicialmente proposta por Campbell et al. (1949). Essas rochas constituem depósitos glaciais, glaciofluviais e fluviais, além de leques ou frentes deltaicas (Caputo, 1984).

Em virtude da ausência de fósseis diagnósticos, a idade de deposição dos litótipos desta unidade foi atribuída com base em 
correlações com unidades cronoequivalentes de outras bacias, ou ainda de acordo com idades de formações fossilíferas sobrejacentes (Santos, 2005).
Desta forma, Aguiar (1971) conferiu a esta unidade idade siluro-devoniana, ao passo que Moore (1963) atribuiu a ela idade ordoviciana a eo-siluriana.

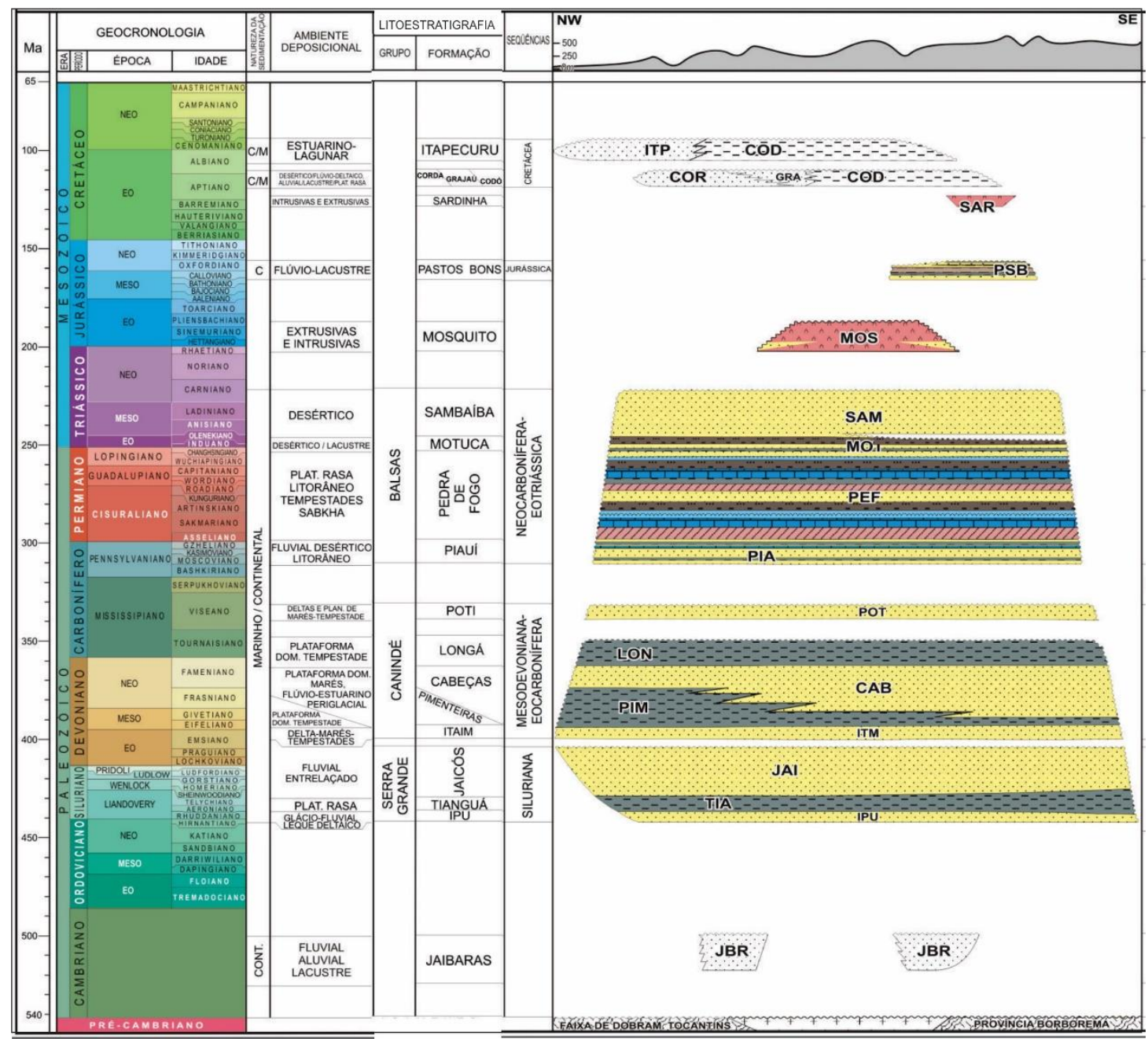

Figura 2 - Carta Estratigráfica da Bacia do Parnaíba (Vaz et al., 2007).

A Formação Ipu apresenta espessura máxima de 350 metros (Vaz et al., 2007) e é caracterizada por arenitos, arenitos conglomeráticos, conglomerados e diamictitos. As estruturas sedimentares mais abundantes são as estratificações cruzadas acanaladas e tabulares. Uma parte das rochas desta formação consiste de depósitos glaciogênicos retrabalhados por processos flúvio-glaciais; outra parte está relacionada a depósitos de leques aluviais (Caputo, 1984).

Sobreposta concordantemente aos litótipos da Formação Ipu ocorrem as rochas da Formação Tianguá, que apresentam espessura máxima de 200 metros (Vaz et al., 2007). Nesta unidade foram encontrados macrofósseis do gênero Monograptus, que atribuem idade siluriana para esta seção (Caputo \& Lima, 1984).

A Formação Tianguá registra a primeira ingressão marinha da Bacia do Parnaíba, sendo representada por folhelhos cinza-escuros, bioturbados, arenitos cinza-claros, finos a médios, feldspáticos, bem como por intercalações de siltitos e folhelhos cinzaescuros, bioturbados e micáceos (Vaz et al., 2007). Esses litótipos são interpretados como depositados em ambiente marinho raso, sob ação de ondas (Góes \& Feijó 1994).

Por fim, a Formação Jaicós, que apresenta cerca de $380 \mathrm{~m}$ de espessura máxima (Vaz et al., 2007), é representada por conglomerados com alta maturidade textural e mineralógica, intercalados com arenitos grossos de cor cinza esbranquiçada, exibindo, em geral, estratificações cruzadas acanaladas. Estes litótipos foram interpretados como depositados em contexto fluvial. Nesta unidade também não foram encontrados macrofósseis, e por isso, sua 
idade é controversa. Todavia, Grahn (1992 apud Santos \& Carvalho 2009) identificou microfósseis que indicam sedimentação ocorrida no Siluriano e Devoniano.

O limite superior desta formação é pouco evidenciado em virtude da semelhança entre os litótipos da Formação Jaicós e os da sobreposta
Formação Itaim, dificultando a identificação de uma provável discordância (Caputo \& Lima, 1984). As rochas dessa formação exibem estratificações cruzadas produzidas pela migração de barras cascalhosas de sistema fluvial entrelaçado. Esta unidade encerra o ciclo transgressivo-regressivo do Grupo Serra Grande.

\section{ANÁLISE ESTRATIGRÁFICA}

\section{Estratigrafia de Sucessões Fluviais}

A Estratigrafia de Sequências é o ramo da geologia que trata do estudo de estratos geneticamente relacionados, associados a um arcabouço de superfícies cronoestratigráficas significativas (Posamentier \& Vail 1988). Essa ciência derivou-se da sismoestratigrafia, que surgiu na década de 1960 e possibilitou a correlação de seções sísmicas gerando imagens tridimensionais, bem como a integração com dados de poços que permitiram a identificação da geometria dos estratos e descontinuidades físicas no registro sedimentar (Posamentier \& Vail 1988).

Os primeiros estudos acerca dessa ferramenta foram realizados pelos pesquisadores da Exxon Research Company, liderados por Peter Vail, que utilizou a associação de seções sísmicas para a detecção de relações estratigráficas. Essa pesquisa resultou, em 1977, em uma publicação no best seller da AAPG Memoir 26, e lançou os fundamentos clássicos da Estratigrafia de Sequências (Severiano, 2001).

Os conceitos pioneiros da Estratigrafia de Sequências foram expandidos e refinados, com o avanço das pesquisas, e publicados em trabalhos como os de Vail et al. (1984), Vail (1987), Wilgus et al. (1988) e Van Wagoner et al. (1990).

As publicações de Wilgus et al. (1988) e Posamentier \& Vail (1988) introduziram o uso da Estratigrafia de Sequências também para sucessões continentais. Esses autores sugeriram que a variação do nível de base e o consequente espaço de acomodação controlavam a deposição aluvial, extrapolando assim, a aplicação da estratigrafia de sequências para um contexto continental. Segundo esses autores, a preservação dos depósitos fluviais é controlada, principalmente, pela criação do espaço de acomodação.

O parâmetro "espaço de acomodação" foi definido por Jervey (1988) como o espaço disponível para potencial acumulação de sedimentos. No entanto, para que estes sejam preservados, deve haver espaço disponível abaixo do nível de base. Esta definição foi inicialmente pensada para contemplar sistemas desenvolvidos em ambiente marinho, onde o nível de base praticamente se iguala ao nível do mar. Por isso, para melhor englobar os depósitos continentais, Catuneanu (2006) denominou de nível de base a superfície global de referência, na qual a erosão continental e a agradação marinha tendem a ocorrer.

Nesse contexto, diversos autores apresentaram modelos detalhados sobre o tema. Wright \& Marriot (1993) foram os pioneiros nos estudos sobre a relação entre o espaço de acomodação e a sedimentação fluvial. Esses autores associaram as variações do nível de base e do espaço de acomodação subaéreo com a arquitetura fluvial e o desenvolvimento de paleossolos.

Wright \& Marriot (1993) elaboraram, desta forma, um modelo que apresenta três tratos de sistemas: Trato de Sistemas de Nível Baixo (TSNB), Trato de Sistemas Transgressivo (TST; inicial e tardio) e Trato de Sistemas de Nível Alto (TSNA). O TSNB, basal, é caracterizado por pouco espaço de acomodação e por canais amalgamados, de granulometria mais grossa. Neste trato há formação de paleossolos maduros e bem drenados. O TST Inicial apresenta uma crescente, mas baixa taxa de acomodação, sendo por isso, também caracterizado por canais arenosos amalgamados e geração de solos hidromórficos. Já o TST Tardio se desenvolve em condições de aumento na taxa de acomodação, resultando em corpos de canais isolados e desenvolvimento incipiente de solos bem drenados. Por fim, o TSNA caracteriza-se por uma rápida diminuição do espaço de acomodação, favorecendo o melhor desenvolvimento de solos e geração de canais amalgamados.

Para Scherer et al. (2008), em sistemas fluviais, o espaço de acomodação está associado ao nível relativo do mar, mas principalmente ao perfil de equilíbrio, o qual se comporta de maneira distinta de acordo com a distância do sistema em relação à linha de costa. 
Em sistemas fluviais acumulados próximo à linha de costa, o nível do mar é o fator dominante sobre o comportamento do perfil de equilíbrio. Desta forma, a sedimentação fluvial, assim como a marinha, obedecerá a curva sinusoidal de variação eustática, podendo ser definidos três tratos de sistemas: de nível baixo, transgressivo e alto (Scherer et al., 2008).

Por outro lado, em sistemas fluviais acumulados distantes da linha de costa, o clima, a tectônica e o influxo sedimentar apresentam maior controle do que o exercido pelo nível do mar sobre comportamento do perfil de equilíbrio fluvial (Blum \& Törnqvist, 2000). Por isso, diversos autores acham equivocado o uso das terminologias dos tratos de sistemas e das superfícies limítrofes em sucessões continentais.

Assim, atualmente, a maioria dos autores prefere utilizar a denominação de tratos de sistemas de alta e baixa acomodação. Essas denominações foram introduzidas por Dahle et al. (1997) e aplicadas por Martinsen et al. (1999). Este último trabalho foi um marco para a definição de unidades estratigráficas não marinhas.

Martinsen et al. (1999) reconheceram apenas dois tratos para as sequências fluviais: o trato de sistemas de baixa acomodação, caracterizado pelo rebaixamento do nível de base, alta razão areia/lama e por canais fluviais amalgamados; e o trato de sistemas de alta acomodação, formado durante a elevação do nível de base, e consequente aumento do espaço de acomodação e abundante ocorrência de sedimentos de planície de inundação. Esses tratos são delimitados pelos limites de sequências e por uma superfície de expansão, a qual é distinguida pelo predomínio de fácies pelíticas.

Para a análise estratigráfica da Seção Siluriana da Bacia do Parnaíba, objeto deste trabalho, foram utilizadas as terminologias tratos de sistemas de nível de base baixo, transgressivo e alto, visando abranger os depósitos fluviais presentes na seção estudada. Foram utilizadas, ainda neste trabalho, as terminologias grande, moderado e pequeno espaço de acomodação, termos adaptados dos conceitos defendidos por Dahle et al. (1997), Martinsen et al. (1999), entre outros.

\section{Análise 1D}

A análise 1D da Sequência Siluriana foi realizada a partir do estudo detalhado dos perfis litológicos associados aos de raios gama, aliado a consultas às pastas dos poços.

$\mathrm{O}$ estudo deste conjunto de dados permitiu a caracterização de litofácies, de acordo com a assinatura nos perfis de raios gama; o reconhecimento dos sistemas deposicionais seguiu o proposto na literatura.

A análise da relação vertical das litofácies, identificadas anteriormente, possibilitou a caracterização de unidades de hierarquia inferior, denominadas aqui de ciclos, baseandose nas tendências de variação textural, sejam de afinamento ou de engrossamento textural para o topo; esses ciclos equivalem, em termos de hierarquia, às parassequências (sensu Posamentier et al., 1988 e Van Wagoner et al., 1988). Os ciclos foram, posteriormente, agrupados em conjuntos de ciclos, os quais foram definidos com base no grau de amalgamento exibido pelos pacotes areníticos, sendo assim diferenciados: intervalo cujos ciclos se mostram bastante amalgamados foi denominado de conjunto de ciclos com pequeno espaço de acomodação; intervalo em que os ciclos exibem algumas intercalações de níveis mais delgados de pelitos foram relacionados a um conjunto de ciclos com moderado espaço de acomodação e, por fim, intervalo onde os níveis de pelitos são frequentes e mais espessos foram associados a um conjunto de ciclos com grande espaço de acomodação. Estes conjuntos foram, posteriormente, associados a tratos de sistemas.

A porção basal da Sequência Siluriana é assinalada por depósitos fluviais da Formação Ipu que se encontram sobrepostos discordantemente ao embasamento (Figura 3). Nos poços estudados, este intervalo é caracterizado por espessas camadas de arenito com estratificações cruzadas, amalgamadas e localmente intercaladas com delgados níveis de folhelho (Figura 3). Este intervalo, relacionado a depósitos fluviais, é sobreposto por um nível de pelito, descrito na literatura como depositado em ambiente marinho de plataforma rasa, interpretado a partir da ocorrência de Monograptus sp segundo Caputo \& Lima (1984).

Este nível representa a camada mais basal da unidade sobreposta, a Formação Tianguá. Na base deste nível foi posicionada a Superfície Transgressiva (ST; Figura 3), que apresenta caráter regional. Essa superfície representa a primeira incursão marinha desta sequência e registra o afogamento dos depósitos fluviais da 
Formação Ipu, que são sobrepostos por do embasamento (cristalino ou metasdepósitos marinhos.

Todo este intervalo, que possui como limite Trato de Sistemas de Nível Baixo (TSNB; inferior a Discordância Pré-Siluriana, no topo Figura 3).

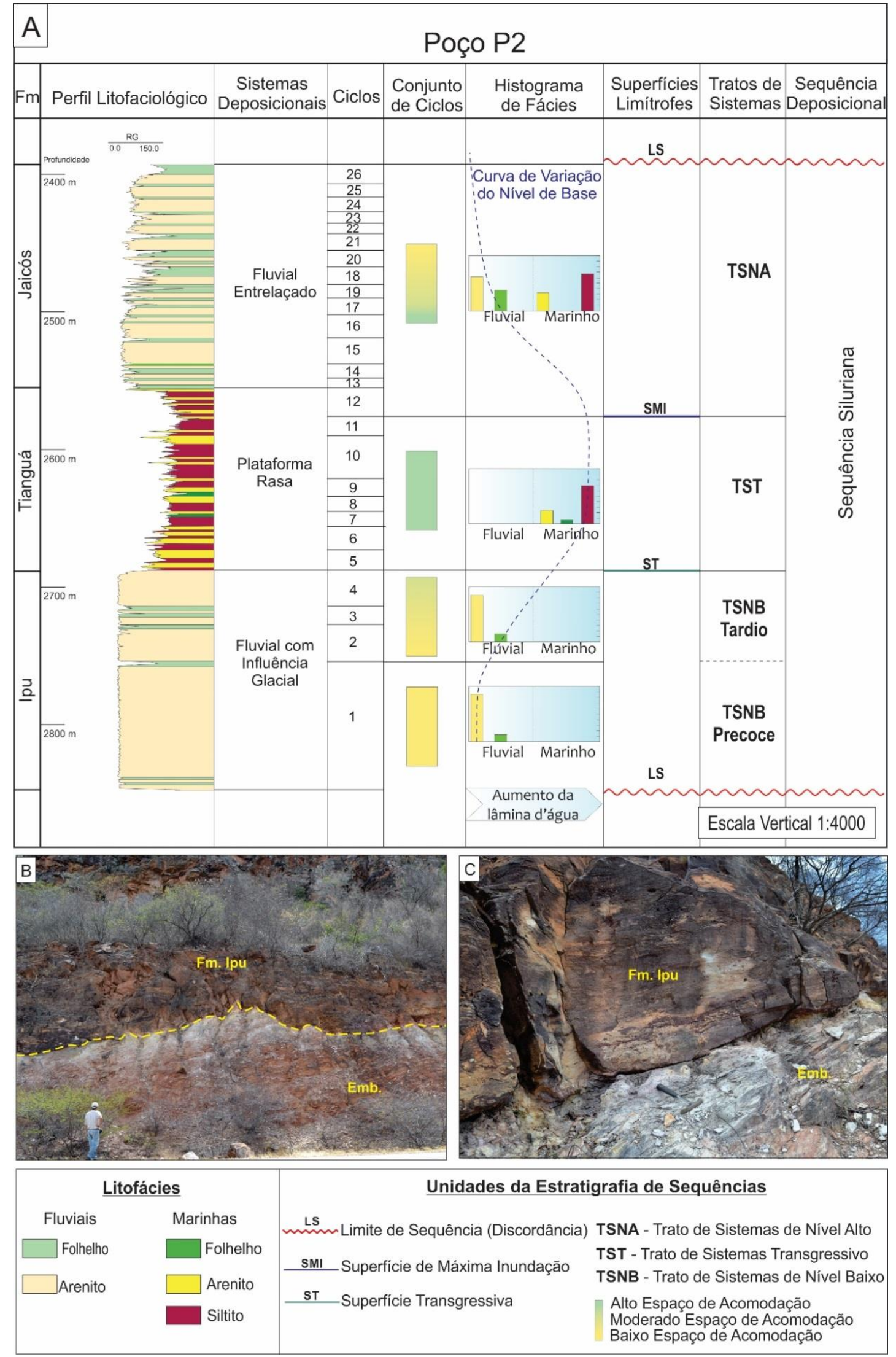

Figura 3 - A) Diagrama 1D do poço P2 do intervalo correspondente à Sequência Siluriana. Em B e C) Arenitos da Formação Ipu, pertencentes ao TSNB, em discordância sobre o embasamento. 

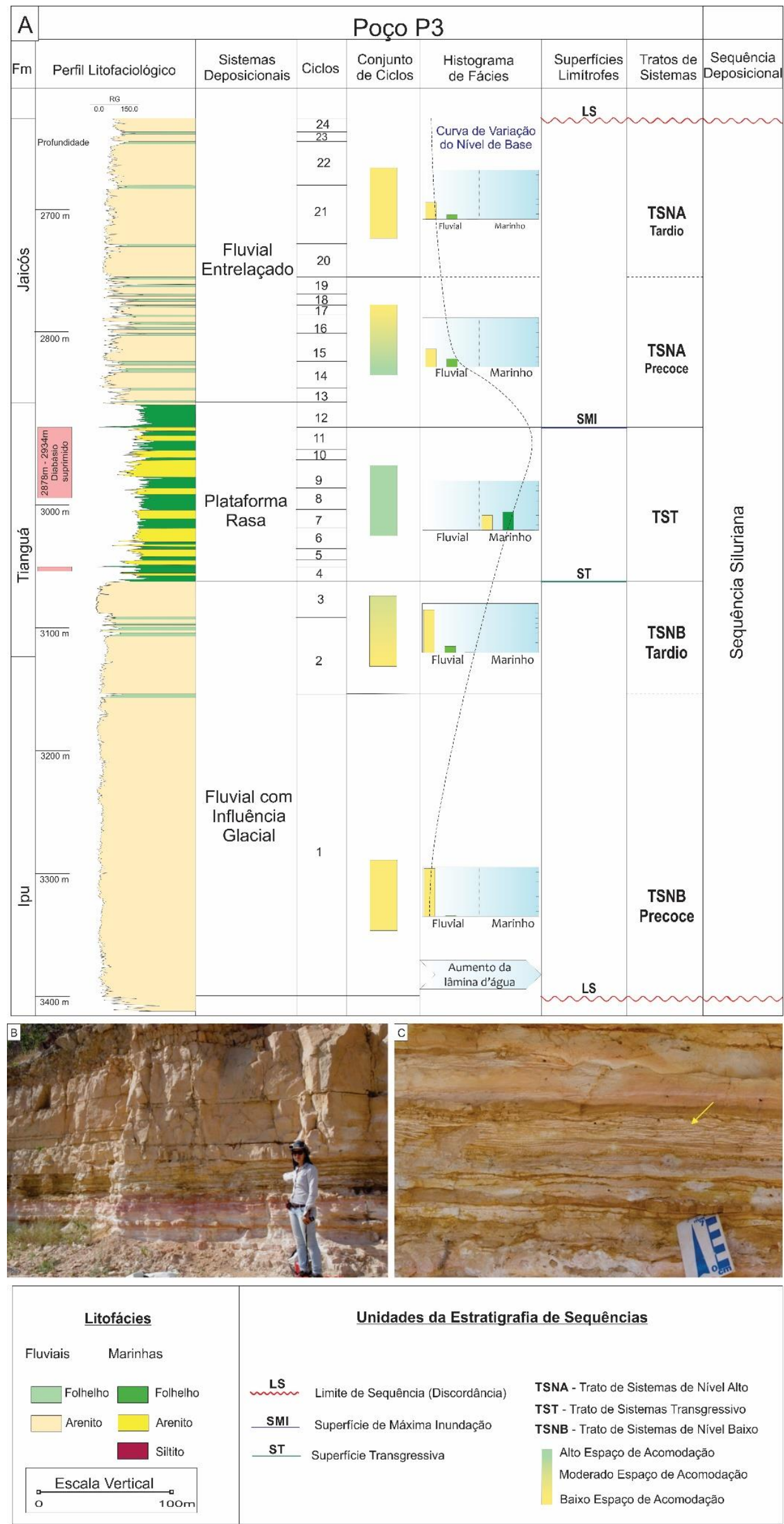

Figura 4 - A) Diagrama 1D do Poço P5 do intervalo correspondente à Sequência Siluriana. Em B) Intercalações de arenito e pelito, pertencentes ao TST. C) Laminações cruzadas por onda (seta amarela). 
O TSNB, nos poços estudados, exibe em sua porção inferior vários estratos de arenito amalgamados, e na porção superior intercalações mais frequentes de folhelhos. Tal fato tornou possível reconhecer, na maioria dos poços estudados, dois conjuntos de ciclos, cujas características denotam terem sido depositados sob condições de pequeno espaço de acomodação na porção inferior, e um conjunto de ciclos com moderado espaço de acomodação, relativo à porção superior do TSNB. Assim, este trato de sistemas pôde ser compartimentado em dois intervalos, nomeados neste trabalho, por TSNB precoce e TSNB tardio (Figura 3).

Interpreta-se que durante a deposição do TSNB precoce prevaleceu baixa, mas crescente, taxa de criação do espaço de acomodação, fato este comprovado pela presença de corpos arenosos amalgamados de granulometria grossa. Por sua vez, no que tange ao TSNB tardio adota-se que sua geração foi marcada por aumento gradual na taxa de criação do espaço de acomodação, e em decorrência disso, os depósitos de preenchimento de canais fluviais foram, gradativamente, se intercalando a níveis de granulação fina de planície de inundação (Figura 3).

Sobrepostos ao TSNB ocorrem depósitos marinhos rasos, pertencentes à porção inferior e intermediária da Formação Tianguá.

Nos poços estudados, esses depósitos compõem ciclos de engrossamento textural para o topo com fácies pelíticas marinhas (folhelhos e/ou siltitos) na base, que gradam para o topo para delgados níveis de arenito fino marinho raso.

Estes ciclos se agrupam para formar um conjunto de ciclos com grande espaço de acomodação (Figura 4). É nítida, em todos os poços estudados, uma tendência marcante de aumento na quantidade de pelitos para o topo, juntamente com a diminuição da quantidade de camadas de arenito e aumento expressivo nos valores de raios gama (Figura 4).

Nos poços estudados este intervalo é representado por ciclos progradacionais que juntos compõem um conjunto de ciclos retrogradacional.

Todo este intervalo registra uma importante fase transgressiva e foi associado ao segundo trato de sistemas da sequência estudada, o Trato de Sistemas Transgressivo (TST).

Esta tendência de aumento na radioatividade nos perfis de raios gama termina em um nível de folhelho que representa a maior expansão dos depósitos marinhos em direção ao continente; neste nível de folhelho foi posicionada a Superfície de Máxima Inundação (SMI). Desta forma, o TST é limitado, em sua porção basal, pela Superfície Transgressiva e, no topo, pela SMI (Figura 4).

A partir da SMI, os valores de raios gama começam a diminuir e os ciclos passam gradativamente a conter quantidade maior de arenitos, revelando o início de uma fase regressiva. Esta fase tem início com os depósitos marinhos da porção superior da Formação Tianguá e se estende até os depósitos fluviais da Formação Jaicós (Figura 5). Todo este intervalo foi associado ao Trato de Sistemas de Nível Alto (TSNA; Figura 5).

A exemplo do TSNB, o TSNA também pôde ser compartimentado em dois intervalos, denominados de TSNA precoce e TSNA tardio, de acordo com os tipos de conjuntos de ciclos presentes. A porção inferior deste trato de sistemas é marcada por um conjunto de ciclos com moderado espaço de acomodação, caracterizado pela ocorrência de camadas de arenito intercaladas com níveis delgados de folhelho. Na literatura este intervalo é descrito como de origem fluvial (Caputo \& Lima, 1984; Santos \& Carvalho, 2009). Com base nisso, infere-se aqui que as camadas de arenito correspondem a depósitos de preenchimento de canais fluviais dispersos entre depósitos de granulometria fina depositados na planície de inundação (Figura 5), e associado ao TSNA precoce. Já, a porção superior exibe maior quantidade de camadas de arenito amalgamadas, com subordinados níveis de pelito (Figura 5). Este intervalo é representado por um conjunto de ciclos com baixo espaço de acomodação referente ao TSNA tardio.

Este trato de sistemas e toda a Sequência Siluriana se encerram com a Discordância Eodevoniana, que constitui o limite superior desta sequência, e a limita com a Sequência Mesodevoniana/Eocarbonífera, sobreposta. 

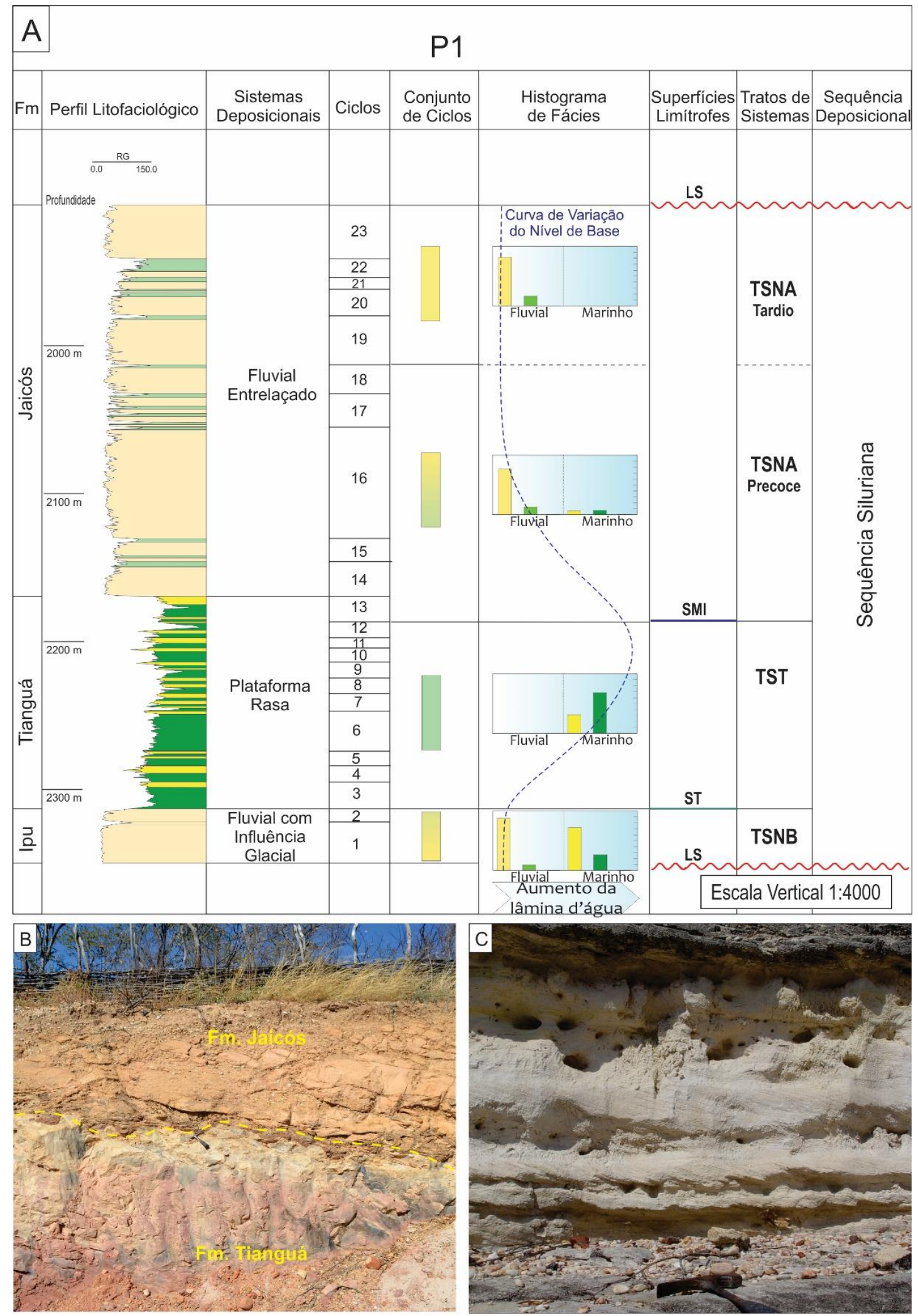

\begin{tabular}{|c|c|c|c|}
\hline \multicolumn{2}{|c|}{ Litofácies } & \multicolumn{2}{|c|}{ Unidades da Estratigrafia de Sequências } \\
\hline Fluviais & Marinhas & Limite de Sequência (Discordância) & TSNA - Trato de Sistemas de Nível Alto \\
\hline Folhelho & Folhelho & SMI Superficie de Máxima Inundacão & TST - Trato de Sistemas Transgressivo \\
\hline Arenito & Arenito & & TSNB - Trato de Sistemas de Nivel Baixo \\
\hline & & ST Superfície Transgressiva & $\begin{array}{l}\text { Alto Espaço de Acomodação } \\
\text { Moderado Espaço de Acomodação } \\
\text { Baixo Espaço de Acomodação }\end{array}$ \\
\hline
\end{tabular}

Figura 5 - A) Diagrama 1D do Poço P1 do intervalo correspondente à Sequência Siluriana. Em B) contato entre os litótipos das formações Tianguá e Jaicós correspondentes ao TSNA. Em C) camadas tabulares de arenito com estratificação cruzada tabular da Formação Jaicós. 


\section{Análise 2D}

A análise 2D da Sequência Siluriana na Bacia do Parnaíba consistiu na interpretação de três linhas sísmicas, situadas na porção centro norte da bacia, as quais contêm alguns dos poços estudados anteriormente, bem como na confecção de uma seção estratigráfica esquemática (localização na Figura 1). A amarração da sísmica com os poços foi realizada por meio de checkshots.

A análise sismoestratigráfica compreendeu o reconhecimento dos refletores associados às superfícies chaves da Estratigrafia de Sequências, tomando como base aquelas definidas durante a análise 1D, que são: as discordâncias limites inferior e superior, que correspondem,

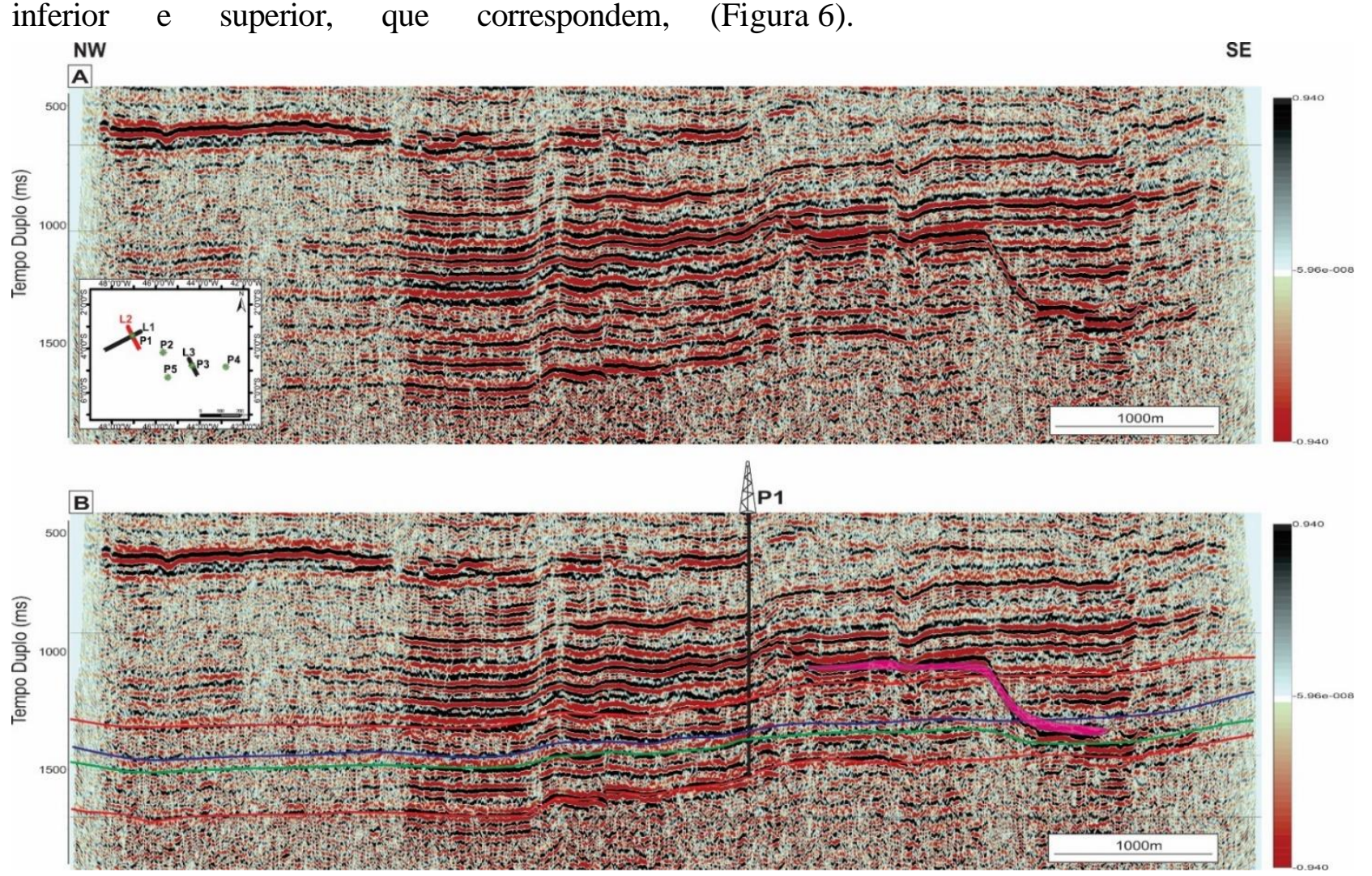

respectivamente, ao topo do embasamento e à Discordância Eodevoniana; a Superfície Transgressiva, que separa os tratos de sistemas de nível baixo do transgressivo; e por fim, a Superfície de Máxima Inundação, que limita os tratos de sistemas transgressivo e de nível alto.

O limite inferior da sequência (LS), topo do embasamento, foi posicionado no último refletor bem definido e de mais continuidade da linha sísmica onde há grande variação de impedância acústica causada pelo contato entre rochas metamórficas (que exibem sismofácies caóticas) e sedimentares (que apresentam sismofácies contínuas). Este posicionamento foi confirmado pela amarração sísmica-poço (Figura 6).

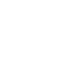

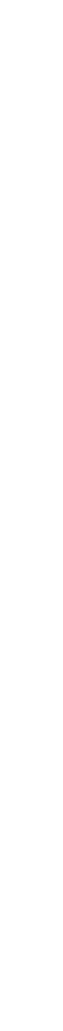

Figura 6 - Linha Sísmica 2 não interpretada (A) e interpretada (B) apresentando as superfícies cronoestratigráficas identificadas na análise 1D. Em vermelho os Limites das Sequências (LS); em verde a Superfície Transgressiva (ST) e em azul a Superfície de Máxima Inundação (SMI). Em cor rosa destaque para a ocorrência de corpos de diabásio.

A Superfície Transgressiva (ST) foi demarcada, com o auxílio da interpretação contida nos poços, na transição entre as fácies areníticas da Formação Ipu para as fácies pelíticas da Formação Tianguá. Nesta passagem o coeficiente de reflexão é positivo em virtude da passagem da onda sísmica de uma camada com menor para uma com maior velocidade (Figura 6).

A Superfície de Máxima Inundação (SMI), nos poços posicionada no mais radioativo nível de folhelho da Formação Tianguá, devido à ausência de critérios diagnósticos como terminações em downlap da seção sobreposta ou em truncamento aparente da seção subjacente, bem como pela inexistência de um significativo contraste de impedância acústica, somente pôde ser bem caracterizada nas proximidades dos poços (Figura 6).

O limite superior da Sequência (LS), passagem das formações Jaicós e Itaim, é representado pela discordância Eodevoniana (Figura 6). Este, sismicamente, apresenta baixo 
contraste de impedância acústica, que se deve à ocorrência, acima e abaixo da discordância, de arenitos pertencentes às formações Jaicós e Itaim, respectivamente. Entretanto, como mais acima deste limite ocorre um intervalo onde os refletores se mostram bastante expressivos e contínuos, os quais foram interpretados como correspondentes às rochas pelíticas da Formação

Pimenteiras, foi possível assinalar este limite (Figura 6). Desta forma, e em seguida, a partir da definição destas superfícies estratigráficas foi possível delimitar os tratos de sistemas. Sendo assim, o intervalo definido entre o limite inferior da Sequência e a Superfície Transgressiva foi associado ao Trato de Sistemas de Nível Baixo; aquele entre as superfícies Transgressiva e de Máxima Inundação foi correlacionado ao Trato de Sistemas Transgressivo; e o último intervalo, que abrange a porção situada entre a Superfície de Máxima Inundação e o limite superior da

Sequência (Discordância Eodevoniana) foi assinalado como o Trato de Sistemas de Nível

\section{Alto (Figura 6).}

Não foi possível através da interpretação sismoestratigráfica compartimentar os tratos de sistemas de nível baixo e alto em precoce e tardio, assim como realizado mediante análise $1 \mathrm{D}$, pois tais intervalos têm pequena espessura, não podendo ser visualizados em escala sísmica.

\section{Análise da Seção Estratigráfica}

Para completar a análise estratigráfica 2D foi confeccionada uma seção estratigráfica esquemática com direção NW-SE, com objetivo de se compreender o comportamento, nestes poços, das unidades genéticas e superfícies estratigráficas identificadas na análise 1D (Figura 7).

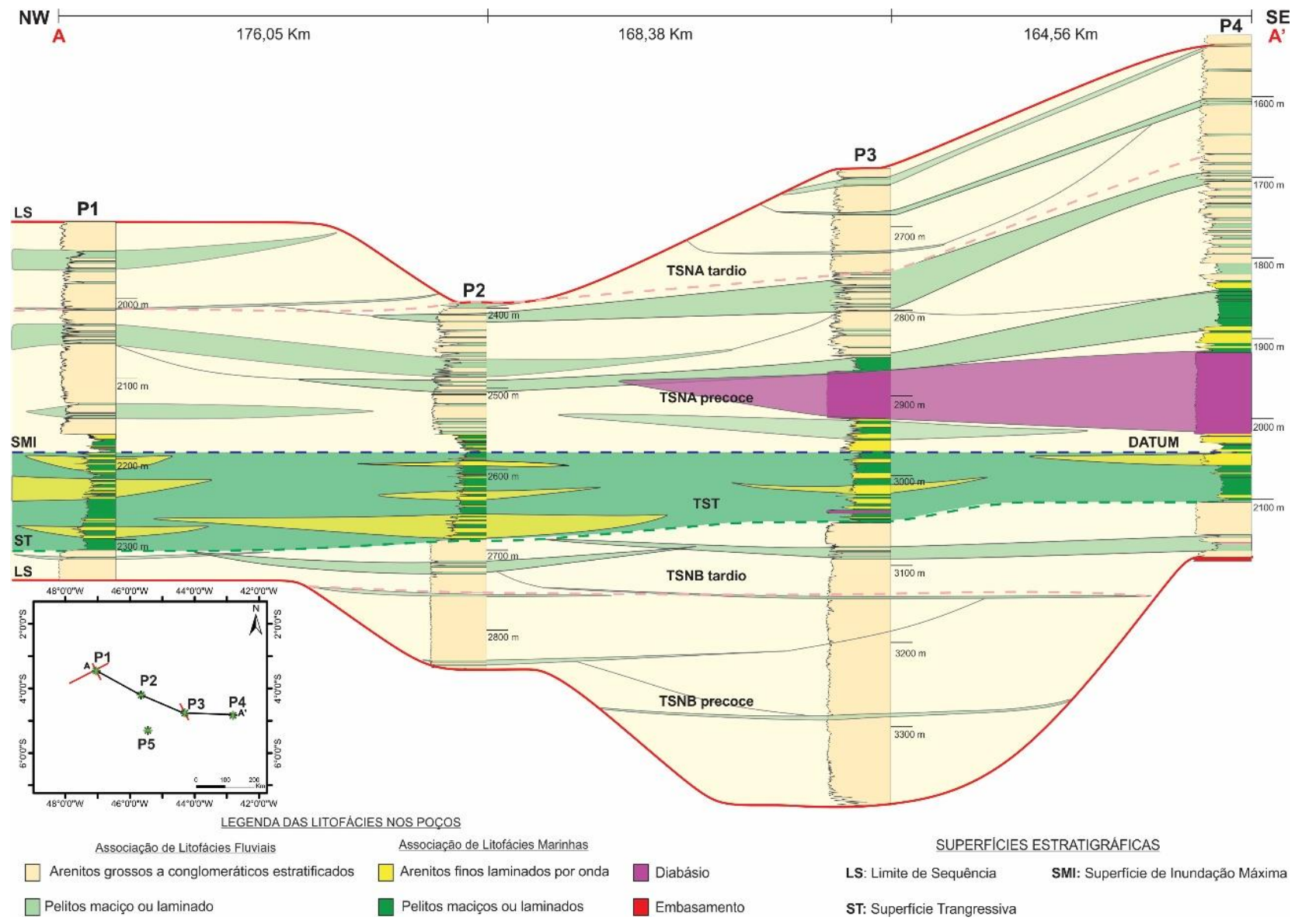

Figura 7 - Seção esquemática NW-SE de correlação dos poços P1, P2, P3 e P4 mostrando os cinco intervalos reconhecidos: TSNB precoce, TSNB tardio, TST, TSNA precoce e TSNA tardio.

A seção estratigráfica elaborada correlaciona quatro dos cinco poços estudados (P1, P2, P3 e P4) e teve a Superfície de Máxima Inundação (SMI) escolhida como datum, já que dentre as demais é a que representa um evento de maior representatividade na bacia.

O TSNB é o intervalo mais espesso da sequência, sendo caracterizado, em sua porção inferior, por espessas camadas de arenito fluvial, que se dispõem de forma amalgamada e vão se adelgaçando em direção ao topo, dando lugar a pacotes cada vez mais frequentes de folhelho também de origem fluvial.

O TST apresenta, aproximadamente, mesma 
espessura ao logo de toda a seção, e é assinalado pela ocorrência níveis de pelitos intercalados com níveis delgados de arenito em uma ambiência marinha plataformal. Por fim, o TSNA inicia com os depósitos mais recentes da Fm. Tianguá e se encerra com os litótipos da Fm. Jaicós. Sendo assim, apresenta em sua porção inferior, camadas de arenitos intercalados com níveis de folhelho que se tornam, para o topo, progressivamente mais amalgamados com a concomitante diminuição dos níveis de folhelho. $\mathrm{Na}$ porção superior do TSNA a quantidade de folhelhos diminui, ao passo que se aumenta a espessura das camadas de arenito, que se tornam novamente amalgamadas, atestando uma diminuição do espaço de acomodação.

\section{MODELOS ESTRATIGRÁFICOS EVOLUTIVOS}

Com o objetivo de ilustrar a evolução do cenário deposicional durante a formação da Sequência Siluriana foram confeccionados modelos estratigráficos evolutivos para cada trato de sistemas identificado.

A sequência inicia-se com a deposição do TSNB precoce (Figura 8A), o qual equivale aos litótipos mais basais da Formação Ipu, e representam espessos pacotes de arenito, amalgamados, com raros níveis de folhelho e siltito. Pela presença de corpos amalgamados de arenito e a quase ausência de pelitos infere-se que sse trato desenvolveu-se em condições de deposição baixo espaço de acomodação.

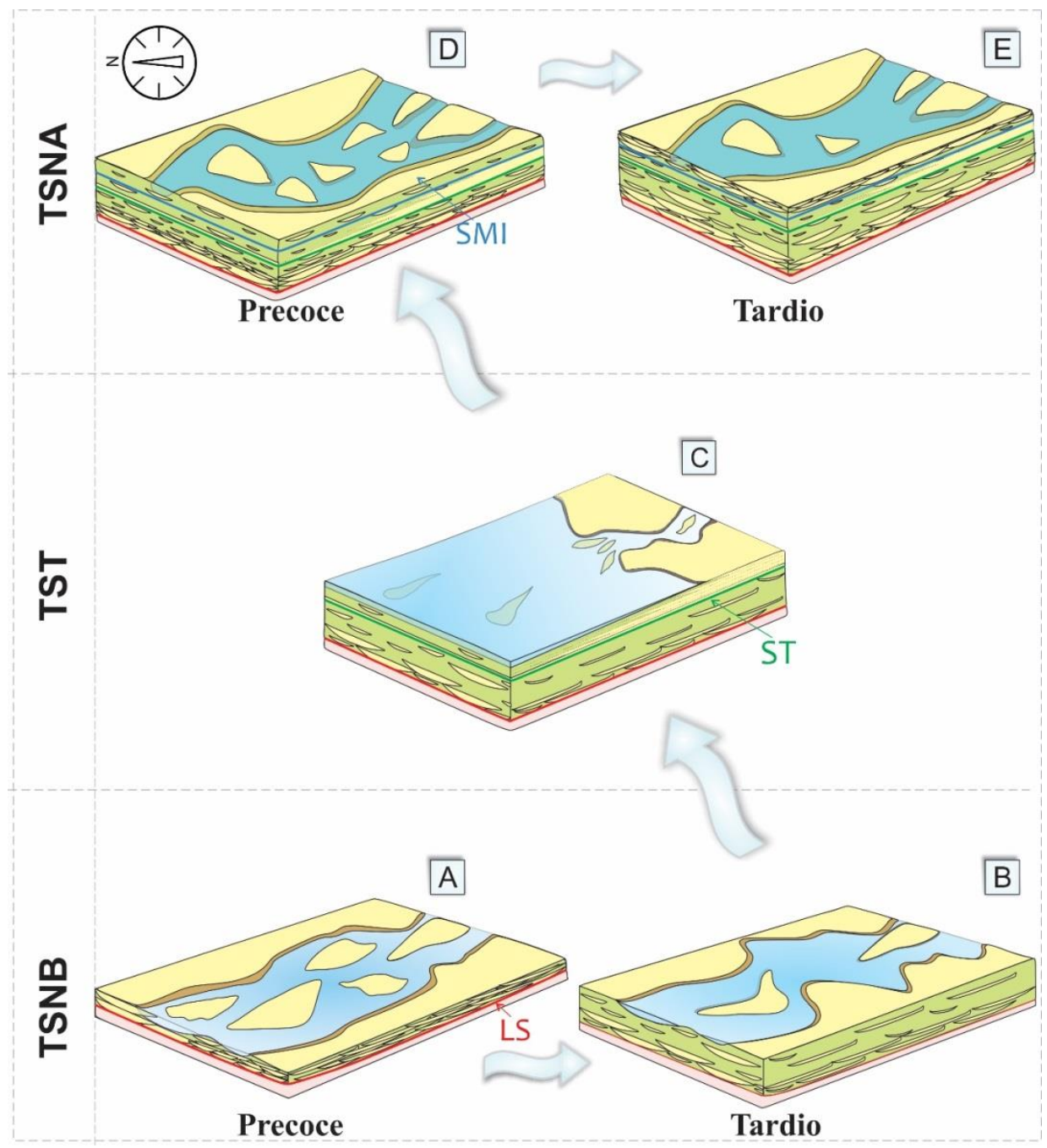

Figura 8 - Modelos de evolução sedimentar idealizados que representam a evolução da Sequência Siluriana da Bacia do Parnaíba. A) Trato de Sistemas de Nível Baixo Precoce; B) Trato de Sistemas de Nível Baixo tardio; C) Trato de Sistemas Transgressivo; D) Trato de Sistemas de Nível Alto precoce e E) Trato de Sistemas de Nível Alto tardio. Os blocos diagramas foram orientados com base em dados de paleocorrentes fluviais que indicam fluxo para noroeste.

O TSNB tardio (Figura 8B), que se segue, é representado por espessos pacotes de arenito fluvial, porém com maior intercalação de níveis de folhelho, indicando o início do aumento gradual na taxa de variação do espaço de acomodação. O TSNB tardio se encerra na 
Superfície Transgressiva (ST) a qual representa a primeira incursão marinha na bacia e assinala o momento em que o nível de base começa a subir. A partir desta superfície tem-se o início da deposição do Trato de Sistemas Trangressivo (TST).

O TST (Figura 8C) corresponde às porções inferior e intermediária da Formação Tianguá, que são compostas por camadas de folhelho e siltito marinhos rasos, intercalados com delgadas camadas de arenito, também marinho. Esse trato foi gerado em condições de deposição com grande espaço de acomodação e se estende até a Superfície de Máxima Inundação (SMI). A partir desta dá-se o início da sedimentação do Trato de Sistemas de Nível Alto (TSNA).

O TSNA precoce (Figura 8D) é constituído pelos litótipos da porção superior da Formação Tianguá e pelos depósitos mais basais da
Formação Jaicós. Este intervalo é caracterizado por pacotes de arenito, inicialmente marinho o qual grada para fluvial, intercalados com delgadas camadas de folhelho e/ou siltito, que igualmente passam de marinhos para fluviais, indicando, assim, o início da diminuição gradual na taxa de variação do espaço de acomodação.

A Sequência Siluriana se encerra com a deposição do TSNA tardio (Figura 8E). Este intervalo corresponde à porção superior da Formação Jaicós e é composto por espessas camadas de arenito fluvial intercaladas a delgadas e subordinadas camadas de folhelho e siltito.

O TSNA tardio é caracterizado por conjunto de ciclos com pequeno espaço de acomodação e se encerra no próprio limite superior da Sequência (LS), o qual equivale à Discordância Eodevoniana.

\section{PROPOSTA ESTRATIGRÁFICA PARA A SEQUÊNCIA SILURIANA}

Com base nas análises estratigráficas realizadas, $1 \mathrm{D}$ e $2 \mathrm{D}$, e nos modelos evolutivos elaborados, foi possível propor um detalhamento da Carta Estratigráfica atual (Vaz et al., 2007) para a Sequência Siluriana. A proposta estratigráfica deste trabalho (Figura 9) assume os mesmos posicionamentos da Carta de
Vaz et al. (2007) para os limites da Sequência Siluriana, sendo estes: a discordância do topo do embasamento, pré-siluriana, limite inferior, e a Discordância Eodevoniana, limite superior. Adota também as mesmas unidades litoestratigráficas e geocronológicas, bem como a mesma interpretação acerca dos sistemas deposicionais.

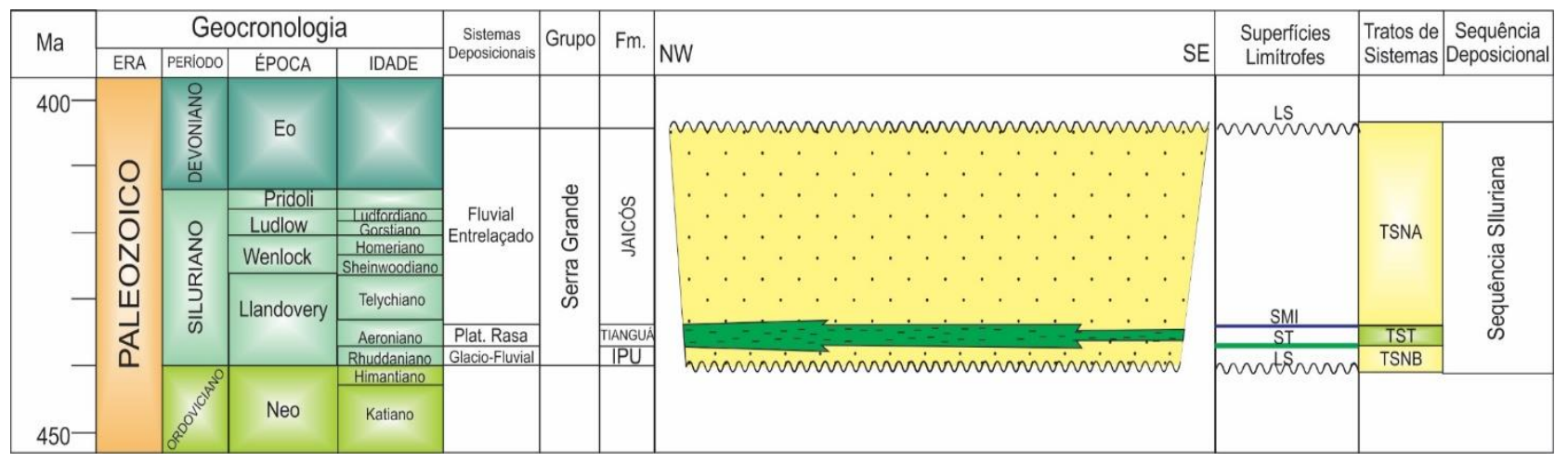

Figura 9 - Proposta de detalhamento da Carta Estratigráfica para a Sequência Siluriana da Bacia do Parnaíba, elaborada com base nos resultados deste trabalho.

Esta proposta, no entanto, acrescenta informações decorrentes da análise estratigráfica de sequências, como posicionamento das superfícies transgressiva e de máxima inundação, além da delimitação dos três tratos de sistemas: os Trato de Sistemas de Nível Baixo, Transgressivo e de Nível Alto.

Além disso, são apresentadas as relações laterais entre as fácies dos três tratos de sistemas, que foram definidas com base em dados de paleocorrentes (Figura 10), os quais indicam direção de fluxo fluvial para noroeste (Figura 8), estando de acordo com o que se observa na seção estratigráfica elaborada.

Assim sendo, o TST foi representado por um pacote pelítico mais espesso na região noroeste e que vai se adelgaçando em direção a sudeste (Figura 9). 

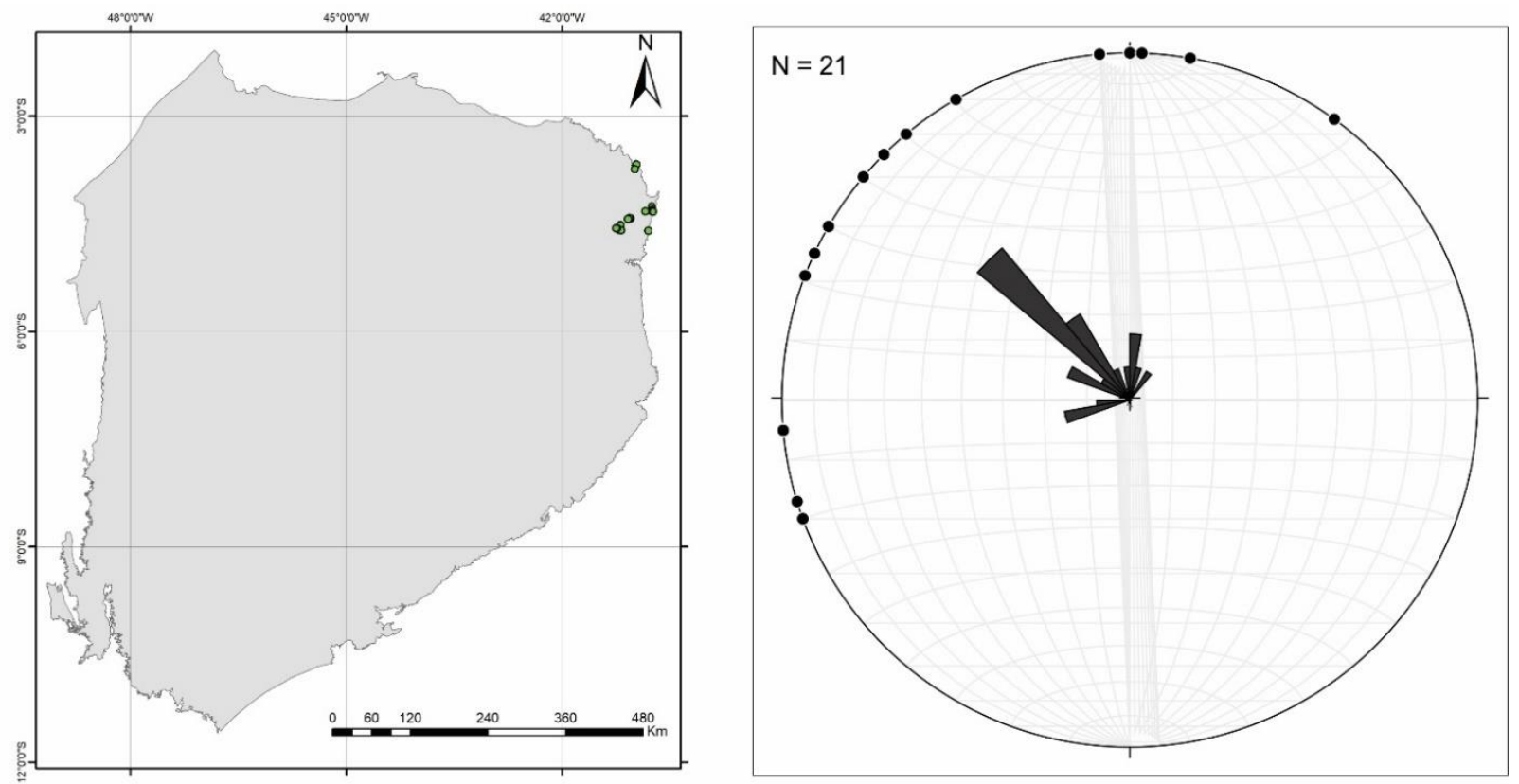

Figura 10 - Diagrama apresentando a orientação das paleocorrentes medidas em 22 afloramentos da Sequência Siluriana, indicados pelos pontos em verde.

\section{CONSIDERAÇÕES FINAIS}

Para a análise estratigráfica da Sequência Siluriana, em virtude desta representar ambos os contextos continental e marinho, optou-se por adotar o espaço de acomodação e a taxa de variação deste espaço como critério na distinção dos tratos de sistemas e dos conjuntos de ciclos.

A ideia que norteia o uso deste critério é comparar entre diferentes intervalos da sucessão siluriana nos poços a maior ou menor ocorrência de corpos amalgamados e assim associar a fases de aumento ou diminuição do espaço de acomodação.

Seguindo esta concepção, a Sequência Siluriana, que corresponde litoestratigraficamente às formações Ipu, Tianguá e Jaicós, pôde ser compartimentada em cinco intervalos de acordo com as tendências de aumento ou diminuição no espaço de acomodação, sendo estes: Trato de Sistemas de Nível Baixo precoce (baixa taxa de criação do espaço de acomodação), Trato de Sistemas de Nível Baixo tardio (moderada taxa de criação do espaço de acomodação), Trato de Sistemas Transgressivo (alto taxa de criação do espaço de acomodação), Trato de Sistemas de Nível Alto precoce (moderada taxa de criação do espaço de acomodação) e, por fim, Trato de Sistemas de Nível Alto tardio (baixa taxa de criação do espaço de acomodação). Este arranjo estratigráfico atesta que a evolução desta sequência é pontuada por um ciclo completo transgressivo-regressivo, onde inicialmente o espaço de acomodação aumenta e depois gradativamente diminui, arranjo este típico de sequências desenvolvidas em fase de sinéclise intracratônica.

\section{AGRADECIMENTOS}

Os autores agradecem ao Programa de Pós-Graduação em Geodinâmica e Geofísica /UFRN; ao Projeto "Geologia e Sistemas Petrolíferos da Bacia do Parnaíba" parceria entre o PPGG/UFRN e a Chevron Brasil, em especial a João Augusto Cunha e Carlos César do Nascimento pela ajuda e discussões sobre o processamento dos dados e a Letícia Hudson pela disponibilização das fotos de campo; por fim, à CAPES pela concessão da bolsa de pesquisa à primeira autora.

\section{REFERÊNCIAS}

AGUIAR, G.A. Revisão geológica da bacia paleozoica do Maranhão. Congresso Brasileiro de Geologia, XXV, São Paulo, 1971. Anais... São Paulo: Sociedade Brasileira de Geologia, v. 3, p. 113-122.

BLUM, M.D. \& TÖRNQVIST, T.E. Fluvial responses to climate and sea-level change: a review and look forward. Sedimentology, 2000. v. 47 p. 2-48.

BRITO NEVES, B.B. \& CORDANI, U.G. Tectonic evolution of South America during the Late Proterozoic. Precambrian Research, v. 53, p. 23-40, 1991.

CAMPBELL, D.F.; ALMEIDA, L.A.; SILVA, S.O. Relatório preliminar sobre a geologia da Bacia do Maranhão. Boletim do Conselho Nacional do Petróleo, Rio de Janeiro, v. 1, p1160. 1949.

CAPUTO, M.V. Stratigraphy, tectonics, paleoclimatology and paleogeography of northern basins of Brazil. Tese 
(Doutorado). Santa Bárbara: Universidade da Califórnia. 583 pp. 1984.

CAPUTO M.V. \& LIMA E.C. Estratigrafia, idade e correlação do Grupo Serra Grande. In: CONGRESSO BRASILEIRO DE GEOLOGIA, XXXIII, Rio de Janeiro, 1984. Anais... Rio de Janeiro: Sociedade Brasileira de Geologia, v. 2, p.740-753.

CAROZZI A.V., FALKENHEIN, F.U.H., CARNEIRO, R.G., ESTEVES, F.R., CONTREIRAS, C.J.A. Análise ambiental e evolução tectônica sinsedimentar da seção siluroeocarbonífera da bacia do Maranhão. Petrobras CENPES, Rio de Janeiro. (Série Ciência - Técnica Petróleo. Seçao de Exploração de Petróleo no 7). 48p. 1975.

CATUNEANU, O. Principles of Sequence Stratigraphy, New York: Elsevier, 386 pp. 2006.

DAHLE, K.; FLESJA, K.; TALBOT, M. R.; DREYER, T. Correlation of fluvial deposits by the use of Sm-Nd isotope analysis and mapping of sedimentary architecture in the Escanilla Formation (Ainsa Basin, Spain) and the Statfjord Formation (Norwegian North Sea). International Conference on Fluvial Sedimentology, Sixth, Cape Town, 199. Abstracts... Cape Town, p. 46.

DELGADO, I.M.; SOUZA, J.D.; SILVA, L.C.; SILVEIRA FILHO, N.C.; SANTOS, R.A.; PEDREIRA, A.J.; GUIMARÃES, J.T.; ANGELIM, L.A.A.; VASCONCELOS, A.M; GOMES, I.P.; LACERDA FILHO, J.V.; VALENTE; C.R.; PERROTTA, M.M.; HEINECK, C.A. Geotectônica do Escudo Atlântico. Brasília: 227-334p., 2003.

DELLA FÁVERA, J.C. Fundamentos de Estratigrafia Moderna. Rio de Janeiro, Ed. UERJ. 264p., 2001.

EMERY, D. \& MYERS, K.J. Sequence Stratigraphy. Ed. Blackwell Science, p. 1-290. 1996.

GÓES A.M.O. \& FEIJÓ F.J. Bacia do Parnaíba. Rio de Janeiro, Boletim de Geociências da Petrobrás, 8(1):57-68. 1994.

GÓES, A.M.O.; SOUZA, J.M.P.; TEIXEIRA, L.B. Estágio exploratório e perspectivas petrolíferas da Bacia do Parnaíba. Boletim Geociências Petrobras, v. 4, p. 55-64, 1990.

GRAHN, Y. Revision of Silurian and Devonian strata of Brazil. Palynology, 16: 35-61. 1992.

HOLZ, M. Estratigrafia de Sequências: Histórico, Princípios e aplicações. Editora Interciência, $1^{\text {a }}$ Edição, Rio de Janeiro, 272 p., 2012.

JERVEY, M.T. Quantitative geological modeling of siliciclastic rock sequences and their seismic expression. In: WILGUS, C.K.; HASTINGS, B.S.; KENDAL, C.G.S.C.; POSAMENTIER, H.W.; ROSS, C.A.; VAN WAGONER, J.C. (Eds) Sealevel changes - an integrated Approach. Tulsa, SEPM, (SEPM Sp. Pb. \# 42), p. 47-69, 1988.

KEGEL, W. Contribuição para o Estudo do Devoniano da Bacia do Parnaíba. Boletim da Divisão de Geologia e Mineralogia 141: 1-48. 1953.

MARTINSEN, O.J.; RYSETH, A.; HELLAND-HANSEN, W.; FLESCHE, H.; TORKILDSEN, G.; IDIL, S. Stratigraphic base level and fluvial architecture: Ericson Sandstone (Campanian), Rock Springs Uplift, SW Wyoming, USA. Sedimentology, v. 46, p. 235-259, 1999.

MIZUSAKI, A.M.P. \&THOMAZ FILHO, A. "O Magmatismo Pós-Paleozóico no Brasil”. In: MANTESSO-NETO, V.; BARTORELLI, A.; CARNEIRO, C.D.R.; BRITO NEVES, B.B. (eds). Geologia do Continente Sul-Americano: Evolução da obra de Fernando Flávio Marques de Almeida. 1 ed. capítulo 17, São Paulo, Beca, 2004.

MOORE, B. Geological Recconaissance of the Southwest Corner of Maranhao Basin. Petróleo Brasileiro S.A., Região de Exploração do Norte, Belém, Brasil. Relatório Interno ${ }^{\circ}$. 210. 74p. 1963.

POSAMENTIER, H.W. \& VAIL, P.R. Eustatic controls on clastic deposition II - Conceptual Framework. In: WILGUS, C.K.; HASTINGS, B.S; KENDALL, C.G.ST.C.; POSAMENTIER,
H.W.; ROSS, C.A.; VAN WAGONER, J.C. (eds). Sea-level Changes - An Integrated Approach. STulsa, Oklahoma: SEPM Geology, Special Publication, n. 42, p. 125-154, 1988.

POSAMENTIER, H.W. \& ALLEN, G.P. Siliciclastic sequence stratigraphy: concepts and applications. SEPM Concepts in Sedimentology and Paleontology, n. 7, 210 p., 1999.

SANTOS V.H. 2005. Sequências Siluro-Devoniana e Eocarbonífera da Bacia do Parnaíba, Brasil, como Análogos para a Explotação de Hidrocarbonetos. Tese (Doutorado em Geociências), Universidade Federal de Pernambuco. CTG. Geociências, 209 pp. 2005.

SANTOS, M.E.C.M \& CARVALHO, M.S.S. Paleontologia das Bacias do Parnaíba, Grajaú e São Luís. $2^{\text {a }}$ Edição- Rio de Janeiro: CPRM-Serviço Geológico do Brasil, 194 pp. 2009.

SCHERER, C.M.S. Ambientes Fluviais. In: PEDREIRA DA SILVA, A.J.C.L.; ARAGÃO, M.A.N.F.; MAGALHÃES, A.J.C. (Orgs). Ambientes de Sedimentação Siliciclástica do Brasil. Rio de Janeiro, 2008. p. 102-130.

SEVERIANO, R.H.J.P. Estratigrafia de Sequências: Fundamentos e Aplicações. São Leopoldo, RS: Editora da Universidade do Vale do Rio dos Sinos. 428 p., 2001.

SMALL, H.L. Geologia e suprimento de água subterrânea no Piauí e parte do Ceará. Recife: Inspetoria de Obras Contra Secas, serie 1-D. public. 32, 146 p. 1914.

VAIL, P.R.; MITCHUM, R.M. JR.; TODD, R.G.; WIDMIER, J.M.; THOMPSON, S.; SANGREE J.B.; BUBB, J.N.; HATLELID, W.G. Seismic stratigraphy and global changes of sea-level. In C.E. PAYTON (ed.), Seismic stratigraphy applications to hydrocarbon exploration. American Association of Petroleum Geologists, Memoir 26, p. 49-212, 1977.

VAIL, P.R. Seismic stratigraphy interpretation using sequence stratigraphy, Part 1: Seismic stratigraphy interpretation procedure. AAPG Studies in Geology, Tulsa, v. 27, p. 1-9, 1987.

VAIL, P.R.; HARDENBOL, J.; TODD, R.G. Jurassic unconformities, chronostratigraphy, and sea-level changes from seismic stratigraphy and biostratigraphy. Tulsa, Oklahoma: AAPG Studies in Geology, Memoir 36, p.129-144, 1984.

VAN WAGONER, J.C.; POSAMENTIER, H.W.; MITCHUM, R.M.; VAIL, P.R.; SARG, J.F.; LOUTIT, T.S.; HARDENBOL, J. An overview of sequence stratigraphy and key definitions. In: WILGUS C.K., HASTINGS B.S., KENDAL C.G.ST.C., POSAMENTIER H.W. ROSS C.A., VAN WAGONER J.C. (eds.) Sea level changes - an integrated approach. Tulsa, SEPM Special Publication, p. 39-45. 1988.

VAN WAGONER, J.C.; MITCHUM, R.M.; CAMPION, K.M. \& RAHMANIAN, V.D. Siliciclastic sequence stratigraphy in well logs, cores, and outcrops: concepts for high-resolution correlation of time and facies. AAPG Methods in Exploration Series, n. 7, 1990.

VAZ, P.T.; REZENDE, N.G.A.M.; WANDERLEY FILHO, J.R.; TRAVASSOS, W.A. BACIA DO PARNAÍBA. IN: MILANI, E.J.; RANGEL, H.D.; BUENO, G.V.; STICA, J.M.; WINTER, W.R.; CAIXETA, J.M.; PESSOA NETO, O.C. (eds.) Bacias sedimentares brasileiras - cartas estratigráficas. Boletim de Geociências da Petrobras, v. 15, p. 253-263, 2007.

WILGUS, C.K.; HASTINGS, B.S.; KENDALL, C.G.ST.C.; POSAMENTIER, H.W.; ROSS, C.A. \& VAN WAGONER, J.C. (Eds.) Sea-level changes: an integrated approach. Society of Economic Paleontologists and Mineralogists Special Publication, 42, p. 407, 1988.

WRIGHT, V.P. \& MARRIOTT, S.B. The sequence stratigraphy of fluvial depositional systems: the role of floodplain sediment storage. Sedimentary Geology, v. 86, p. 203-210, 1993.

Submetido em 13 de junho de 2017 Aceito em 5 de outubro de 2018 